$551.501 .8: 551.501 .77$

\title{
The Radar Wave Attenuation Caused by Precipitation Particles
}

\author{
by \\ N. Kodaira \\ Meteorological Research Institute \\ (Received November 1, 1963)
}

\begin{abstract}
The microwave attenuation produced by rain is calculated by taking account of the drop size distribution. Attenuation constants thus obtained are scattered about in some ranges, and the width of scatter is wider at X-band. The width at $10 \mathrm{~mm} / \mathrm{hr}$ is respectively about 1.2 , $6.2,3.3,0.9 \mathrm{db}$ for the wave lengths of $8.6 \mathrm{~mm}, 3.2 \mathrm{~cm}, 5.6 \mathrm{~cm}, 10 \mathrm{~cm}$, whereas the reflectivity $Z$ varies by about $8 \mathrm{db}$ for distribution of the same precipitation rate and the same drop size distribution.
\end{abstract}

As a result, the measurement of rainfall by the attenuation of $\mathrm{K}$ band has a merit that it is less influenced by the drop size distribution.

\section{Introduction}

Entering a space in which rain is falling, the energy of the radar beam is dissipated in the following ways:

i) by the range attenuation, inversely proportional to the square of the range ;

ii) by absorption by atmospheric gases;

iii) by absorption by hydrometeors ;

iv) by scattering of the beam by hydrometeors.

The absorption by hydrometeors is usually expressed in terms of rainfall rate $R \mathrm{~mm} / \mathrm{hr}$, using the averaged drop size distribution. Since the drop size distribution tends to vary in different rainfalls having the same precipitation rate, the scatter width of the attenuation constants should be investigated.

\section{Attenuation caused by a single water drop}

The attenuation cross section $Q_{t}$ of a single water droplet is given by KeRR as follows :

$$
Q_{t}=\frac{-\lambda^{2}}{2 \pi} R_{e} \sum(2 n+1)\left(a_{n}+b_{n}\right),
$$

where $\lambda$ is the free-space wave-length, and $a_{n}$ and $b_{n}$ spherical Bessel functions with the arguments $\alpha$ and $m$, respectively. They are given by: 


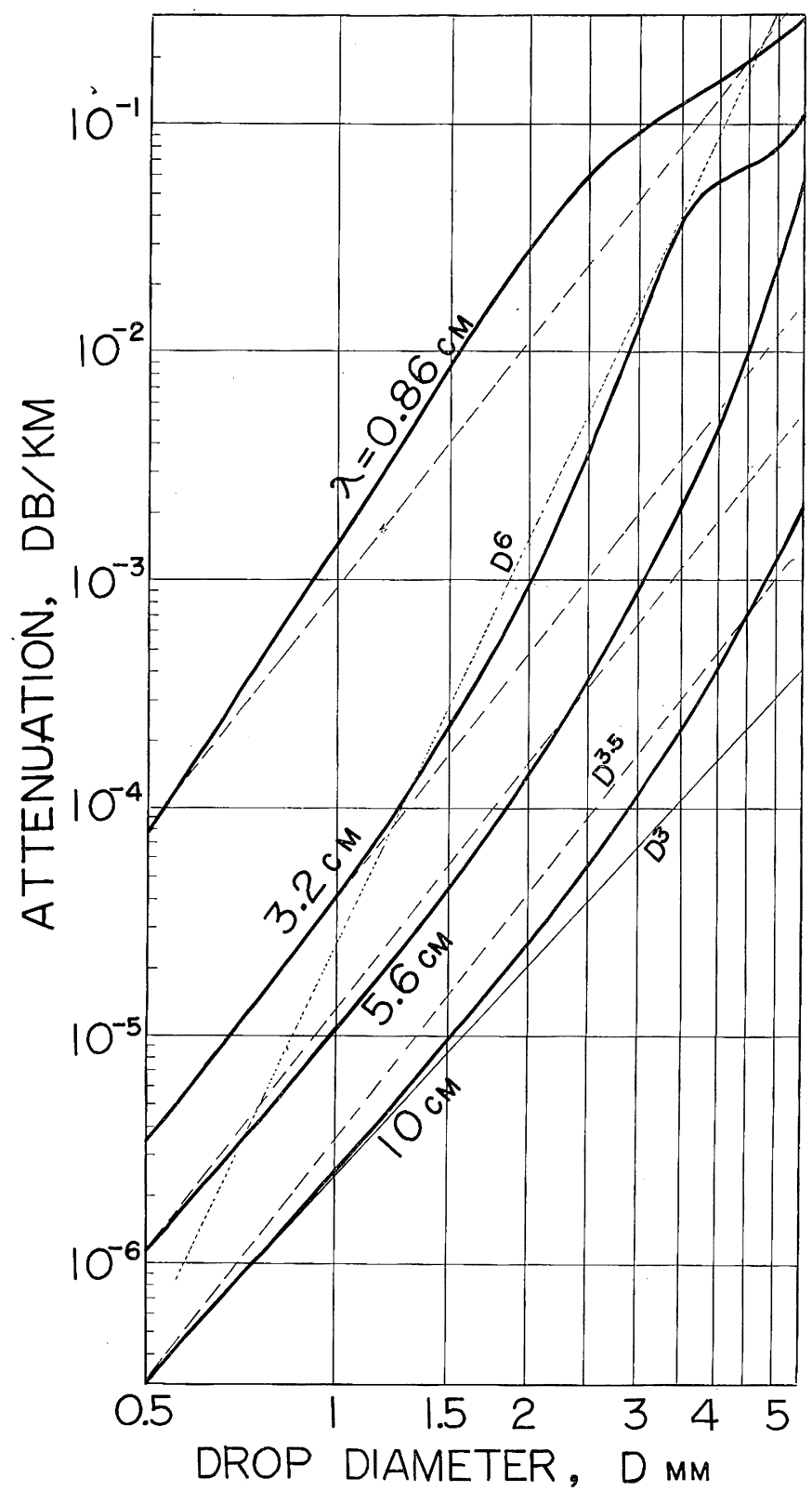

Fig. 1. Microwave attenuation by a single drop having a diameter of $D$, for various wave length. Dotted lines shows the $D^{3.5}$ which is proportional to rainfall intensity $R$. 


$$
\alpha=\frac{\pi D}{\lambda}, \quad m=n-i k \text { (complex refractive index of water) }
$$

In spite of the complexity of Eq. (1), the calculations are tabulated by LowAN for the particular complex argument. Fig. 1 shows the attenuation constant for a single drop having a diameter of $D$ per cubic meter of space, and these curves are calculated by IMAI and KODAIRA from LowAN's tables with some interpolations. In this figure, calculations are made for droplets ranging from 0.5 to $5.5 \mathrm{~mm}$ in diameter.

An examination of Fig. 1 gives that the curves of $Q_{t}$ are to some extent unparallel to the dashed lines of $D^{3.5}$, which is proportional to rainfall intensity $R$, in case of the drop falling at their terminal velocity $v$ of $k D^{0.5}$. If the curves $Q_{t}$ are parallel to the curve of $D^{3.5}$, attenuation constant $K$ of the rainfall rate $R$ will be determined uniquely from $R$ unrelated to drop size distribution $N_{D}$, because both $R$ and $K$ are functions of $\sum N_{D} D^{3.5}$.

\section{Attenuation caused by the rain}

The relations between radar reflectivity $Z$ and rainfall intensity $R$ are scattered about around the regression lines of the well-known form:

$$
Z=B R^{\beta}
$$

The scatter of the relation has been observed by many investigators, and the constants $B$ and $\beta$ depend on the types of rain. $B$ and $\beta$ can be determined from the drop size distribution of the rain and are classified into several weather situations by Fujwara. Following his classification, 10 typical combinations of $B$ and $\beta$ are considered as shown in Table 1.

Table 1. Combinations of $B$ and $\beta$ for 10 weather situations.

\begin{tabular}{c|rcc|cccc|cc|c}
\hline \hline Type & I & II & III & IV & V & VI & VII & VIII & IX & X \\
\hline$B$ & & 80 & & \multicolumn{4}{|c|}{200} & & 400 & 700 \\
$\beta$ & 1.6 & 1.8 & 2.0 & 1.2 & 1.6 & 1.8 & 2.0 & 1.2 & 1.6 & 1.6 \\
\hline
\end{tabular}

The combination of this table will cover sufficiently all the $Z-R$ relations as shown in Fig. 2. The plots in this figure indicate the measured values of individual $Z-R$ relations, observed in many weather situations and at various locations. MARSHALL and Palmer proposed the following drop size distribution:

$$
N_{D}=n_{0} e^{-A D}
$$

where $N_{D}$ is the number of drops of diameter $D$ per unit volume. Supposing that the constants $n_{0}$ and $A$ are functions of $R$, they are given by

$$
\begin{aligned}
& n_{0}=n R^{m}, \\
& \Lambda=A R^{-a},
\end{aligned}
$$

The constants $n, m, A$ and $a$ are related to $B$ and $\beta$ of equation (2), as follows : 


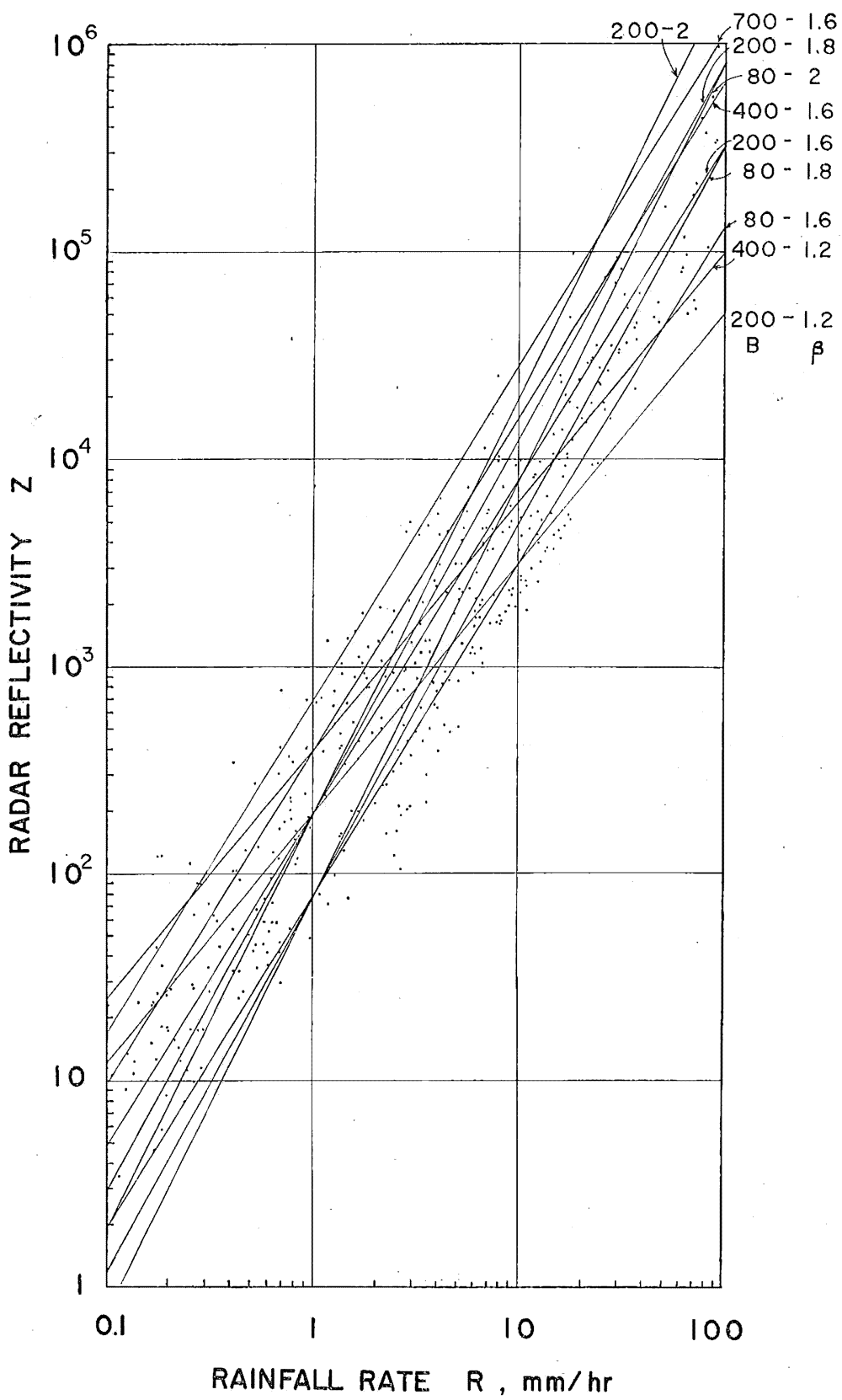

Fig. 2. $Z-R$ relations for various types of $B$ and $\beta$ combinations. Dots are calculated values from the actual measurements of drop size distributions. 


$$
\begin{gathered}
Z=10^{12} \int_{0}^{\infty} N_{D} D^{6} d D=10^{12} \frac{6 ! n_{0}}{A^{7} R^{-7 a}}=B R^{\beta}, \\
R=3.6 \times 10^{4} \frac{\pi}{6} \int_{0}^{\infty} n_{0} e^{-1 D} v D^{3} d D=\frac{0.6 \pi 10^{4} \Gamma(4.5) k n R^{m}}{A^{4.5} R^{-4.5 a}},
\end{gathered}
$$

where $v$ is the falling velocity of drops, proportional to $D^{0.5}$ up to the drop diameter of $4.5-5 \mathrm{~m}$. (Spillhous) And for $v$ in equation (7), the relation

$$
v=k D^{0.5}
$$

is used. The discrepancies of $v D^{3}$ in Eq. (7) from the values computed from actual falling velocities are less than $15 \%$, if the maximum diameter is supposed to be 5.5 $\mathrm{mm}$, and drops larger than this tend to break up in falling. Calculation of (6) and (7) gives :

$$
m+7 a=\beta,
$$$$
\text { 4. } 5 a+m=1 \text {, }
$$

and also

\begin{tabular}{|c|c|c|c|c|c|c|c|c|c|c|}
\hline Type & I & II & III & IV & $\mathrm{V}$ & VI & VII & VIII & IX & $\mathrm{X}$ \\
\hline$B$ & & 80 & & \multicolumn{4}{|c|}{200} & \multicolumn{2}{|c|}{400} & 700 \\
\hline$\beta$ & 1.6 & 1.8 & 2.0 & 1.2 & 1.6 & 1.8 & 2.0 & 1.2 & 1.6 & 1. 6 \\
\hline$n$ & \multirow{2}{*}{\multicolumn{3}{|c|}{$\begin{array}{c}0.35 \\
61\end{array}$}} & \multicolumn{4}{|c|}{0.064} & \multicolumn{2}{|c|}{0.019} & 0.0078 \\
\hline$A$ & & & & \multicolumn{4}{|c|}{42} & \multicolumn{2}{|c|}{32} & 26 \\
\hline$a$ & 0.24 & 0.32 & 0.4 & 0.08 & 0.24 & 0.32 & 0.4 & 0.08 & 0.24 & 0.24 \\
\hline$m$ & -0.08 & -0.44 & -0.8 & 0.64 & -0.08 & -0.44 & -0.8 & 0.64 & -0.08 & -0.08 \\
\hline
\end{tabular}

$$
\begin{aligned}
& B A^{7}=720 \times 10^{12} n, \\
& A^{4.5}=3.1 \times 10^{8} n,
\end{aligned}
$$

Thus the constants are listed in Table 2 for the 10 combinations of $B$ and $\beta$.

Table 2. The values of constants $a, m, n$ and $A$ for 10 weather situations.

By making use of these constants of Table 2, we can express $K$, the constant of attenuation by rain of a given intensity,

$$
K=0.4343 \int_{0}^{\infty} N_{d} Q_{t} d D \mathrm{db} / \mathrm{km},
$$

and Fig. 3 shows $K$ in $\mathrm{db} / \mathrm{km}$ for various types of $B$ and $\beta$ combinations.

Fig. 4 is a replotting of Fig. 3 in terms of $K / R$, showing the maximum and minimum limits of the $K / R$ value. In the above calculations, drop size distributions are assumed to be $n_{0} e^{-A D}$ and this does not always fit for all kinds of rain. However, we can see that the attenuation constant is also a function of drop size distribution, 


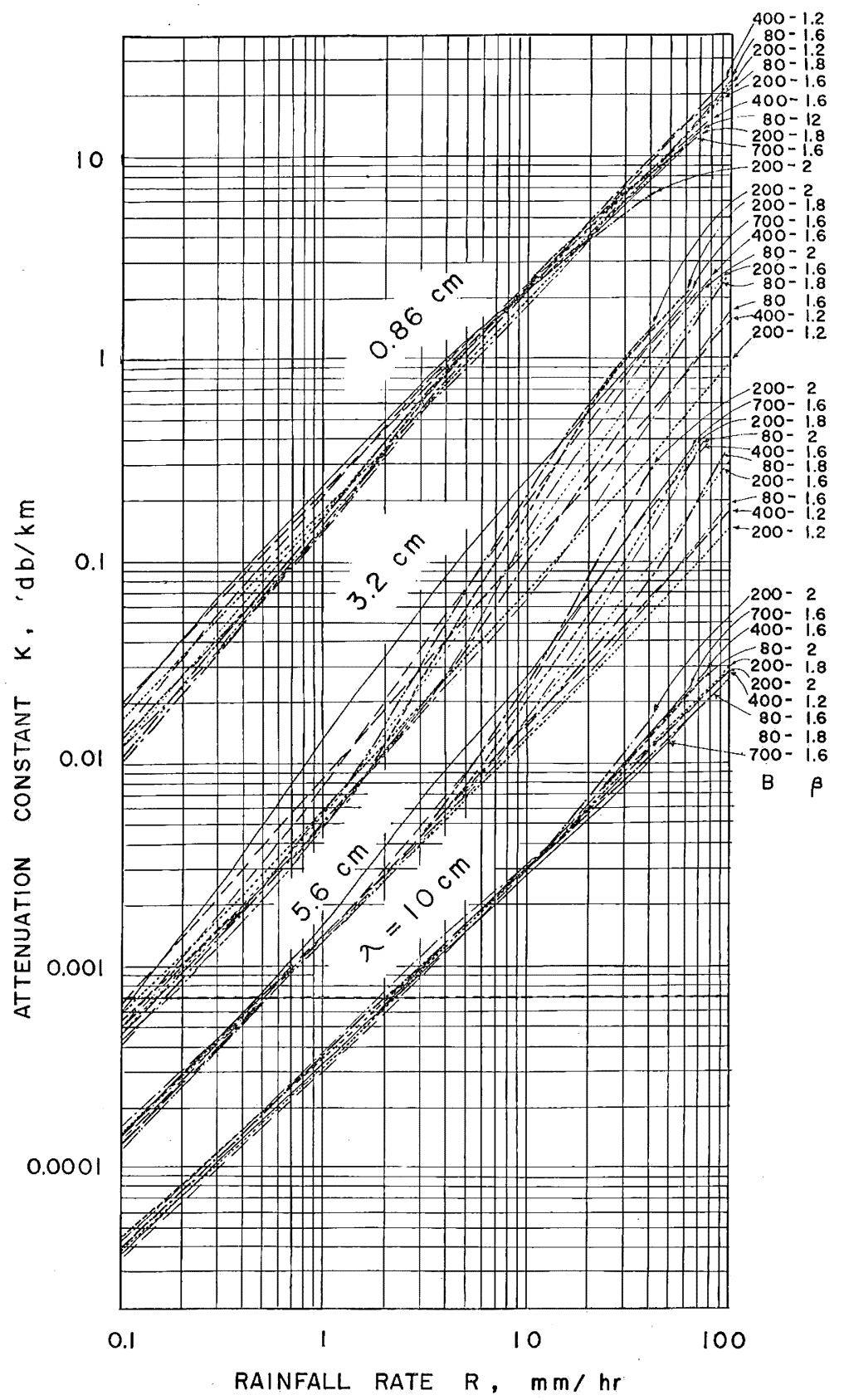

Fig. 3. Attenuation constant $K$ of rain. The dotted line refers to the atmospheric gas attenuation for the wave length of 3. $2,5.6$ and $10 \mathrm{~cm}$. 


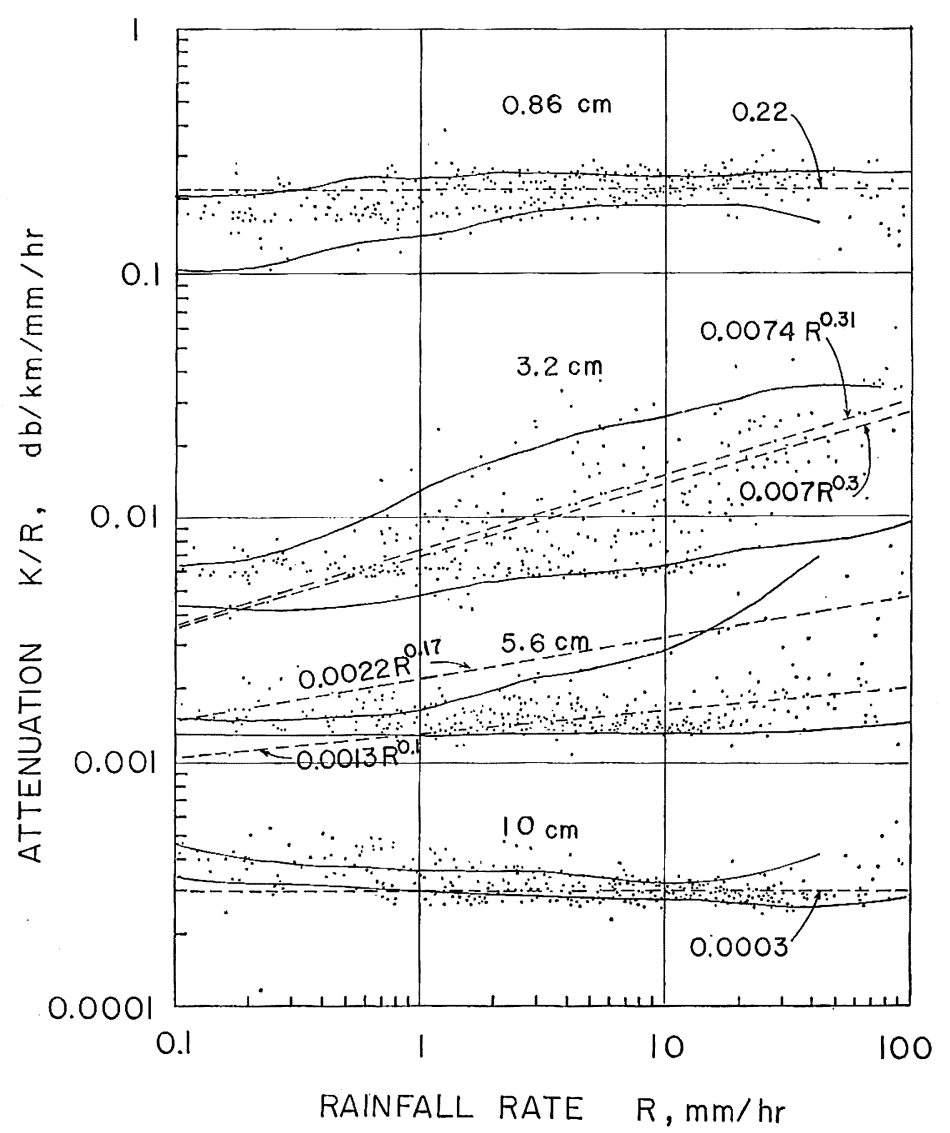

Fig. 4. Scattered width of attenuation constant $K$ replotted from Fig. 3. The dots indicate the calculated values from individual drop size distributions.

and in particular, at some wave lengths it is scattered in a considerably wide range.

For rains of the thunderstorm type, $N_{D}$ cannot be expressed in the form of equation (3), and it is concentrated at a certain value of the diameter. For comparison's sake, drop size data measured in various conditions, as in the case of Fig. 2, have been used for calculation of the attenuation constants, which are plotted in Fig. 4.

The dots in Fig. 4 represent the attenuation constant $K$ calculated from measured distributions of individual rains, including those of the shower type, thunderstorm type and continuous type. Though the data of $50 \mathrm{~mm} / \mathrm{hr}$ or more are not enough compared to the weaker rainfall rate, in most of these cases, the plots of individual attenuation constant are confined within the calculated region of $n_{0} e^{-A D}$ distribution.

It can be concluded that the scatter width of attenuation constants are determined from Fig. 4. This fact probably comes from the evidence that small drops do not effectively contribute to attenuation. The upper and lower limits of constants 
$K$ are compared to the previously published values in Table 3 and they are shown by clotted lines in Fig. 4.

Table 3. Comparison of attenuation constants, $\mathrm{db} / \mathrm{km}$.

\begin{tabular}{c|l|c|c}
\hline \hline Wave length & Extent of $K$ & $K$, GUNN \& EAST & $K$, IMAI \\
\hline $0.86 \mathrm{~cm}$ & $0.15 R-0.25 R$ & $0.22 R$ & - \\
$3.2 \mathrm{~cm}$ & $0.005 R^{1.1}-0.013 R^{1.3}$ & $0.0074 R^{1.31}$ & $0.007 R^{1.3}$ \\
$5.6 \mathrm{~cm}$ & $0.0013 R-0.0015 R^{1.3}$ & $0.0022 R^{1.17}$ & $0.0013 R^{1.1}$ \\
$10.0 \mathrm{~cm}$ & $0.0003 R-0.0035 R$ & $0.0003 R$ & $0.0003 R$ \\
\hline
\end{tabular}

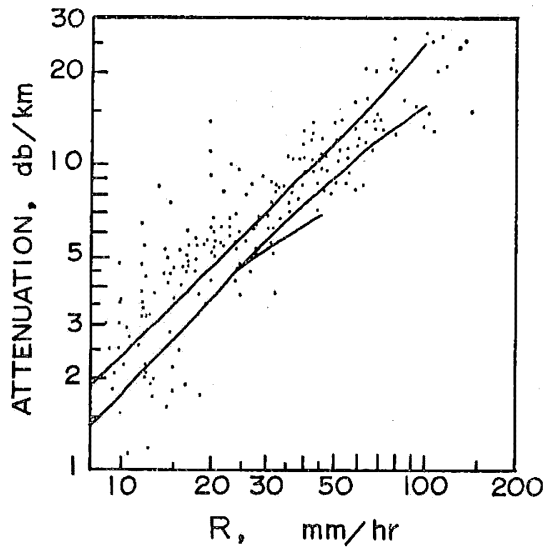

Fig. 5. Attenuation constants of $8.6 \mathrm{~mm}$ wave measured by the transmission experiments.
Attenuation measurements of $8.6 \mathrm{~mm}$ region are carried out by the Radio Research Laboratory, using $400 \mathrm{~m}$ span. An example is plotted in Fig. 5, together with the extent of attenuation constants calculated here. The scattering of attenuation mainly comes from the errors of rainfall measurements. Due to the inhomogeneous nature of rainfalls, this kind of measurement will suffer from the scattering of the measured values, unless a huge number of raingauges of the rainfall intensity measurement type are distributed along the path.

In practical application, as there is atmospheric gas attenuation of about $0.007 \mathrm{db} / \mathrm{km}$ for $X-, C$ - and $S$-bands, the rain attenuation of less than this value can be neglected. The dashed line in Fig. 3 indicates the atmospheric gas attenuation for these three wave lengths.

\section{Conclusion}

The errors inherent in various methods of rainfall measurement due to the drop size distribution are compared in Fig. 6. In this figure the error in $\mathrm{db}$ is the ratio of maximum to minimum of calculated $R$ in relation to a certain value of reflectivity or attenuation under the condition that the drop size distribution or rainfall type is unknown. It is clear that the reflectivity method is rather unreliable even if the attenuation by intervening rain is neglected or compensated. The curve for $8.6 \mathrm{~mm}$ in Fig. 1 is rather close to the $D^{3.5}$ curve, compared with the curves of 3.2 and 5.6 $\mathrm{cm}$. This fact is also shown in the attenuation constant of $8.6 \mathrm{~mm}$ in Fig. 4 which is less influenced by drop size distribution than those of 3.2 and $5.6 \mathrm{~cm}$ are. In view of the results so far achieved, it is very promising to use the $8.6 \mathrm{~mm}$ wave for the measurement of rainfall intensity from the path attenuation under certain circumstances. 


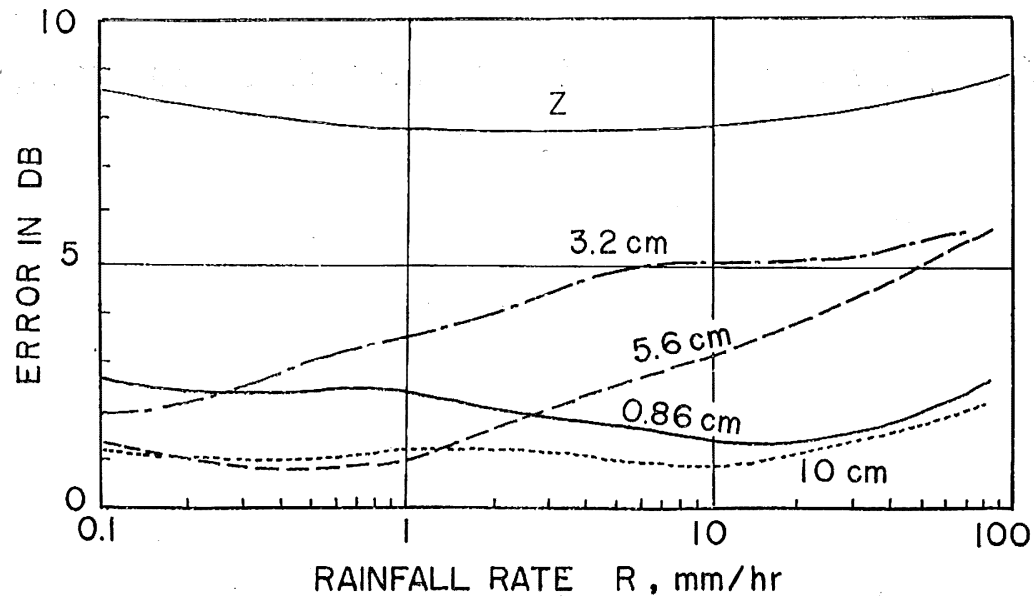

Fig. 6. Comparison of errors due to the drop size distribution for the measurement of $R$. The curve $Z$ shows the error for the method of reflectivity measurement and the other curves refer to the method of attenuation measurement.

Acknowledgement- The author wishes to thank Mr. M. Fujiwara for his kindness to furnish the author with relevant data.

\section{References}

Fusiwara, M., 1960: An analytical investigation of the variability of size distribution of raindrops in convective storms, Proc. 8th Weather Radar Conference, p. 159.

GunN, K.L.S. and T.W.R. EAST, 1954: The microwave properties of precipitation particles, Q.J.R.M.S. 80 , p. 522 .

ImAI, I., 1957: Attenuation of microwaves through rain for various drop size distribution, J. Met. Soc. Japan, II, 75th Ann. Vol. p. 65.

KERR, D.E., 1951: Propagation of short radio waves, MIT Radiation Lab. Series, McGrawHill Book Co.

Kodatra, N. and J. Aoyagr, 1961: On the problems of rainfall measurements by radar, J. Met. Soc. Japan, II, 39, 4, p. 215.

Lowan, A., 1949: Tables of scattering functions for spherical particles. National Bureau of Standard, Washington.

Radio Research Lab., 1960: On the propagation of mm wave, Report No. 46-1.

SpILLнous, A.F., 1948: Drop size, intensity and radar echo of rain, Jour. Met. 5, p. 161.

降水粒子によるレーダー電波の減衰

小平信彦

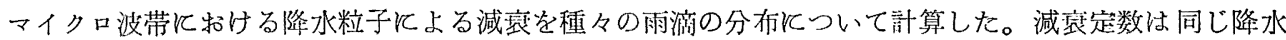
強度飞対してもその粒径分布により買ってきて，その分布の幅は $X$-band の時飞最大となる。10 mm/ hr の封の幅は波長 $0.86,3.2,5.6,10 \mathrm{~cm}$ 飞対してそれぞれ $1.5,6.2,3.3,0.6 \mathrm{db}$ である。一方同じ粒 径分布飞対するレーダ反射因子 $Z$ の幅は約 $8 \mathrm{db}$ であるから， $K$-band の減㿪から平均の降水強度を求め るのは雨滴分布の型による誤差を少なくする.上飞有効である。 